\title{
The angular discretization impact of thermal radiation computations on heat transfer in rooms
}

\author{
Catalin Teodosiu, Viorel Ilie, Raluca Teodosiu
}

\begin{abstract}
The objective of this study is to evaluate the accuracy of CFD (Computational Fluid Dynamics) simulations for airflows driven by buoyancy in heated real scale rooms. In addition, this study is focusing on the influence of angular discretization used for thermal radiation computations in CFD modeling. The numerical results are compared with experimental data from the literature, based on investigations dealing with thermal coupling "room-electric heat sources", using full scale test cells. The results show that there is no sensitivity of radiative heat flux to the walls of the room to angular discretization used in the radiation model. This means that for simple geometries, minimum angular discretization can be used for the radiation model in CFD simulations, leading to important savings in CPU (Central Processing Unit) time. Nevertheless, this deduction must be checked by further work for other configurations.
\end{abstract}

Keywords - thermal radiation, CFD modeling, heat source

\section{Introduction}

The appropriate design of HVAC (heating, ventilation, and air conditioning) systems can be achieved only by taken into account three criteria: thermal comfort of occupants, indoor air quality, and energy efficiency. On the other hand, it is obvious nowadays that these criteria cannot be met without investigations using modern computational techniques. In line with this, the CFD (Computational Fluid Dynamics) approach has been successfully employed for applications dealing with the modeling of different technical systems in the field of building equipment: ventilation systems [1], air conditioned systems [2], radiation panel cooling systems installed in walls [3], radiant cooling ceiling [4], radiant tube heater [5], underfloor heating systems [6], skirting boards heating systems [7], and evaporator and condenser of a rooftop air-conditioning unit [8].

In this context, the objective of this study is to assess the accuracy of CFD simulations for airflows driven by buoyancy in heated real scale rooms. In addition, this study is focusing on the influence of angular discretization used for thermal radiation computations involved in heat transfer phenomena that take place in heated rooms. This analysis is carried out in this study in the case of a small room equipped with electrical heat sources.

Catalin Teodosiu, Viorel Ilie, Raluca Teodosiu

Technical University of Civil Engineering Bucharest

Romania

\section{Acknowledgments}

This work was supported by a grant of the Romanian Ministry of Education and Research, CNCS-UEFISCDI, project number PN-II-ID-JRP-RO-FR2012-0071.
It is worthwhile to mention that the numerical results are thoroughly analyzed based on experimental data.

Consequently, the experimental set-up is first presented, followed by the principal characteristics of the CFD model.

\section{Experimental Set-up}

This study is based on an experimental investigation concerning the thermal coupling of different heat sources with a room [9]. This work was taken into consideration as it makes available complete experimental data: detailed descriptions of boundary conditions and extensive measurements for numerical validation (velocity and temperature fields within the test room, heat transfer to the walls and heat source thermal behavior). The experimental tests were performed in a climatic test room $\left(3.1 \times 3.1 \times 2.5 \mathrm{~m}^{3}\right)$ in steady state conditions on electric linear heat sources. All the walls of this full scale test cell are in contact with adjacent controlled temperature areas (Fig. 1). The electric heat source was positioned near the window and it consists of three elements, $1 \mathrm{~m}$ length each (Fig. 1).
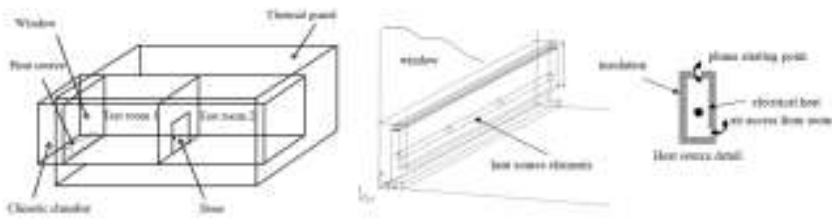

Figure 1. Experimental set-up [9]

During the tests, the length and the power of the heat source were varied in order to assess its behavior. This was correlated to external temperatures imposed at the glass wall. The configuration taken into account in this study is presented in Table I.

TABLE I. EXPERIMENTAL CONFIGURATION [9]

\begin{tabular}{|c|c|c|c|}
\hline $\begin{array}{c}\text { Number of } \\
\text { heat source } \\
\text { elements }\end{array}$ & $\begin{array}{c}\text { Heat source } \\
\text { power }(\mathbf{W})\end{array}$ & $\begin{array}{c}\text { External } \\
\text { temperature }- \\
\text { glass wall }\left({ }^{\circ} \mathbf{C}\right)\end{array}$ & $\begin{array}{c}\text { Thermal guard } \\
\text { temperature } \\
\text { other walls }\left({ }^{\circ} \mathbf{C}\right)\end{array}$ \\
\hline 1 & 591.0 & 5.9 & 23.0 \\
\hline
\end{tabular}

Surface temperatures inside and outside the walls of the test cell were measured using a network of 114 thermocouples ( $24 \times 1$ surface - glass wall and $18 \times 5$ surfaces - other walls) in order to determine the conductive rates and the radiative heat exchanges between walls, as well as between these and the heat source. The thermocouples are type $\mathrm{K}$ (ChromelAlumel), with diameter $2 \times 10^{-4} \mathrm{~m}$ and accuracy $\pm 0.15^{\circ} \mathrm{C}$ [9]. 
These thermocouples were positioned in the surface layer of the outer and inner surfaces (in vis-à-vis) of each wall [9].

The air temperatures and air velocities measurements were carried out using an automatic device that is able to transport the sensors over different planes in the test room. The instruments mounted on this device were omnidirectional hotfilm transducers for air velocity (accuracy: $\pm 3 \%$ of the selected full scale measurement) and type $\mathrm{K}$ (Chromel-Alumel) thermocouples (diameter $2 \times 10^{-4} \mathrm{~m}$ and accuracy $\pm 0.15^{\circ} \mathrm{C}$ ) for air temperature [9].

\section{CFD Model}

The numerical analyses reported in this work are based on a general-purpose, finite-volume, Navier-Stokes solver (Fluent 15.0.0). The main features of the numerical model are summarized in Table II.

TABLE II. CFD APPROACH MAIN ELEMENTS AND HYPOTHESIS

\begin{tabular}{|c|c|}
\hline Feature & Description \\
\hline Fluid & $\begin{array}{l}\text { Air: Newtonian fluid; incompressible; } \\
\text { constant viscosity }\end{array}$ \\
\hline Flow & $\begin{array}{l}\text { Three-dimensional; steady; non- } \\
\text { isothermal; turbulent }\end{array}$ \\
\hline $\begin{array}{l}\text { Computational domain } \\
\text { discretization }\end{array}$ & $\begin{array}{l}\text { Finite volumes; unstructured mesh } \\
\text { (tetrahedral elements); optimum mesh size } \\
\text { (grid independent solutions); } 1,360,245 \\
\text { cells }\end{array}$ \\
\hline Turbulence model & $\begin{array}{l}\text { Transition Shear Stress Transport (SST) } \\
\text { k- } \omega\end{array}$ \\
\hline Radiation model & Discrete ordinates (DO) \\
\hline Heat source description & $\begin{array}{l}\text { Term source (volumetric heat generation } \\
\text { rate) in the energy balance equations of } \\
\text { the cells representing the heat source } \\
\text { discretization }\end{array}$ \\
\hline $\begin{array}{l}\text { Wall boundary } \\
\text { conditions }\end{array}$ & $\begin{array}{l}\text { Convective heat transfer: external } \\
\text { convective heat transfer coefficient and } \\
\text { external air temperature (measured in the } \\
\text { adjacent test room - thermal guard area) }\end{array}$ \\
\hline Numerical resolution & $\begin{array}{l}\text { Segregated implicit solver; diffusion } \\
\text { terms: second order central-difference } \\
\text { scheme; convective terms: second order } \\
\text { upwind schemes; velocity-pressure } \\
\text { coupling: SIMPLE algorithm; } \\
\text { convergence acceleration: algebraic } \\
\text { multigrid (gradient method, Green-Gauss } \\
\text { cell based) }\end{array}$ \\
\hline
\end{tabular}

The geometry of the computational domain is identical to the real configuration of the experimental study. As a result, the linear heat source is represented by its real dimensions (length and diameter) [10].

The discretization of the computational domain is performed by means of an unstructured mesh (finite volumes), using tetrahedral elements. In addition, a mesh refinement was implemented in the plume region. The region considered for the mesh refinement follows the configuration of the heat source [10]. The range of this zone was defined running several mesh sensitive studies, taking into account the precision of the results and the total number of finite volumes, related to central processing unit (CPU) time.

The CFD approach proposed in this work takes into consideration a transition SST k- $\omega$ turbulence model [11], based on the coupling of the SST k- $\omega$ model transport equations [12] with two other transport equations: one for the intermittency, and one for the transition momentum thickness Reynolds number. The reasons to choose this turbulence model are explained in [10].

The radiation heat transfers are computed using the conservative version of the DO (Discrete Ordinates) radiation model [13]. This approach solves the radiative transfer equation written as a transport equation for radiation intensity in the spatial coordinates:

$$
\frac{d L\left(r_{i}, \vec{u}\right)}{d x}+\frac{d L\left(r_{j}, \vec{u}\right)}{d y}+\frac{d L\left(r_{k}, \vec{u}\right)}{d z}=\kappa\left(r_{i}\right)\left[L\left[T\left(r_{i}\right)\right]-L\left(r_{i}, \vec{u}\right)\right]
$$

where $\mathrm{L}$ - radiation intensity, $\mathrm{r}\left(\mathrm{r}_{\mathrm{i}}, \mathrm{r}_{\mathrm{j}}, \mathrm{r}_{\mathrm{k}}\right)$ - position vector, $\mathrm{u}$ direction vector, $\kappa-$ absorption coefficient, $\mathrm{T}-$ absolute temperature and $\mathrm{L}^{0}$ - black body radiation intensity given by:

$$
\mathrm{L}\left[\mathrm{T}\left(\mathrm{r}_{\mathrm{i}}\right)\right]=\sigma \frac{\mathrm{T}^{4}\left(\mathrm{r}_{\mathrm{i}}\right)}{\pi}
$$

where $\sigma$ - Stefan-Boltzmann constant $\left(5.67 \times 10^{-8} \mathrm{~W} / \mathrm{m}^{2} \mathrm{~K}^{4}\right)$.

Equation (1) is added to the principal equations governing the air flow in the CFD model (conservation laws of mass, impulse, and energy).

The DO radiation model resolves (1) for a finite number of discrete solid angles. The number of equations solved is given by the amount of discrete solid angles defined. The solid angles are obtained based on an angular discretization, using control angles that determine the discretization of each octant in the angular space. Consequently, throughout the computational domain, each octant is discretized in $\mathrm{N}_{\theta} \times \mathrm{N}_{\Phi}$ solid angles [14]. These angles are based on the polar and azimuthal angle respectively, defined in the coordinate system (x, y, z), Fig. 2 (angles $\theta$ and $\Phi$ ). As a result, angles $\theta$ and $\Phi$ determine the position of the vector $r$.

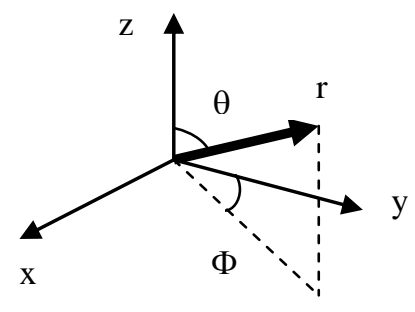

Figure 2. Angular discretization [14]

For three-dimensional calculations, a total number of $8 \mathrm{~N}_{\theta}$ $\mathrm{N}_{\Phi}$ directions are taken into account. In addition, for unstructured grids, the faces of the control volumes are not generally aligned with the overall angular discretization. In 
fact, a part of the elementary (control) angles "enters" and another part "leaves" with respect to the faces of the mesh elements. For this reason, it is necessary to correctly determine the fractions "in" and "out" of control angles. This is achieved by dividing each elementary angle in $\mathrm{N}_{\theta \mathrm{p}}$ and $\mathrm{N}_{\Phi p}$ "pixels", Fig. 3 [14].

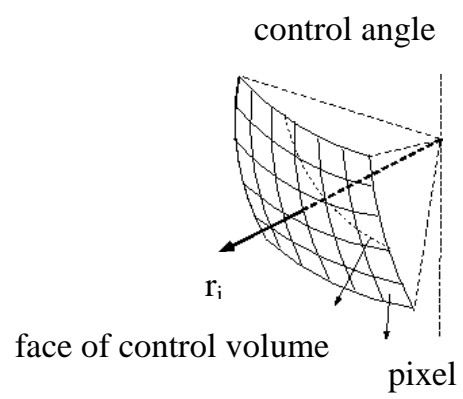

Figure 3. Discretization of elementary angles using "pixels" [14]

Consequently, the energy contained in each "pixel" is treated as "incoming" or "outgoing" to the faces.

As the main objective of this numerical investigation is the impact of angular discretization used for radiant heat fluxes calculations, the method briefly presented above is employed in the case of the experimental set-up previously described, taken into account different number of control angles for each octant in the computational domain.

Finally, the radiative heat transfer modeling is based on the assumption that the indoor air is a non-participating radiation medium. In addition, all surfaces taken into account within the model have the following properties: grey scattering surfaces (transmission and reflection).

Concerning the heat source integration in the CFD model, this is accomplished based on a volumetric heat generation rate which is uniformly distributed within the heater [15].

All thermal boundary conditions in this study are set using experimental data. The thermal boundary conditions for the walls of the test room are therefore imposed based on a convective heat transfer, using an external convective heat transfer coefficient and the external temperature measured in the adjacent zones of the test room - thermal guard spaces. This allows to determine the total heat flux to the walls of the room [10].

\section{Results}

We first present net radiative heat flux to the walls of the test room based on several different angular discretizations, taken into account for the DO radiation model (Table III). It can be noticed a wide range of deviations from the experimental data. There are therefore reasonable results with differences compared with experimental data between 5-10\% (ceiling, east wall, and west wall) but there are also overestimated results, roughly between $20-42 \%$ (south wall and north wall, respectively). These results are surprisingly recorded regardless of the number of control angles used for the angular discretization in the DO radiation model (Table III).

TABLE III. Radiative Heat FluX to the Walls (W)

\begin{tabular}{|c|c|c|c|c|c|}
\hline \multirow{2}{*}{ Wall* } & \multirow{2}{*}{$\begin{array}{c}\text { Experimental } \\
\text { results [9] }\end{array}$} & \multicolumn{4}{|c|}{$\begin{array}{c}\text { Numerical results } \\
\text { (number of control angles for each } \\
\text { octant in the computational domain)** }\end{array}$} \\
\cline { 3 - 6 } & & $(2)$ & $(3)$ & $(4)$ & $(5)$ \\
\hline South & 252.5 & 303.7 & 306.9 & 308.4 & 308.4 \\
\hline North & 27.8 & 39.3 & 41.8 & 42.8 & 43.8 \\
\hline Ceiling & 94.3 & 89.3 & 87.8 & 90.1 & 87.2 \\
\hline East & 42.0 & 45.6 & 45.9 & 45.5 & 45.5 \\
\hline West & 42.0 & 46.4 & 45.3 & 44.2 & 45.6 \\
\hline
\end{tabular}

*The window (behind the heat source) is considered as the "south" wall of the test room (see also Fig. 1).

**Number of pixels used for each control angle is 1 .

In fact, better angular discretization (even using up to 5 control angles for each octant in the computational domain) does not improve the prediction of radiative heat exchange in the heated enclosure, in spite of the complex geometry in the surrounding area of the linear heat source (window wall - Fig. 1). It can be deduced (at least for the case taken into account) that there is no sensitivity of radiative heat flux to the walls of the test room to the DO angular discretization.

In addition, numerical investigations using up to 10 pixels for each elementary angle did not show any major difference compared to calculations carried out based on lower levels of "pixelation".

We studied also the potential impact of better angular discretization for the DO radiation model on the overall air flow in the room. We thus present air velocity contours (Fig. 4) and air temperature contours (Fig. 5) in the median vertical plane of the test cell, normal to the heat source, for minimum angular discretization (2 control angles) and for improved angular discretization (5 control angles) in the DO radiation model.

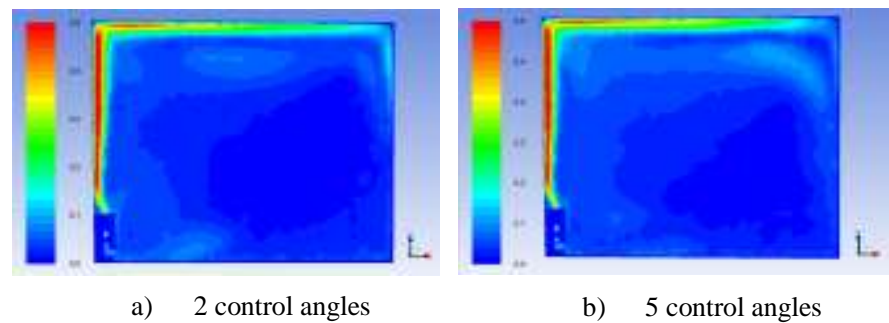

Figure 4. Air velocity contours (m/s) for different angular discretization in the DO radiation model

As expected, considering the results in Table III, there is no influence of the angular discretization, employed in the DO radiation model, on air velocity and air temperature in the room. The apparent differences in Figs. 4 and 5 are mainly due to accuracy of the graphical representations, the numerical values being nearly identical (e.g. Fig. 4, bottom left corner: $0.04 \mathrm{~m} / \mathrm{s}$ versus $0.05 \mathrm{~m} / \mathrm{s}$ and top right corner: $0.06 \mathrm{~m} / \mathrm{s}$ versus 
$0.08 \mathrm{~m} / \mathrm{s}$; Fig. 5, bottom left corner: $22.6^{\circ} \mathrm{C}$ versus $22.7^{\circ} \mathrm{C}$ and top right corner: $25.2^{\circ} \mathrm{C}$ versus $25.4^{\circ} \mathrm{C}$ ). Nevertheless, these slight differences should be elucidated by further investigations.

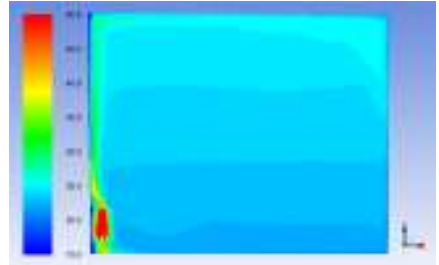

a) 2 control angles

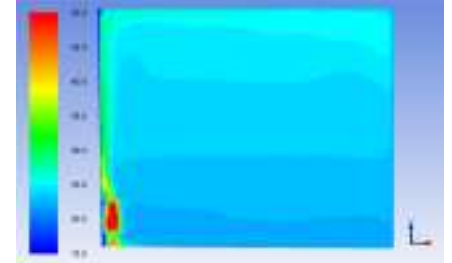

b) 5 control angles
Figure 5. Air temperature contours $\left({ }^{\circ} \mathrm{C}\right)$ for different angular discretization in the $\mathrm{DO}$ radiation model

\section{v. Conclusion}

The CFD model presented in this work is able of predicting natural convective flows in rooms. The methodology developed here can be used to model the thermoaeraulic behavior of heated rooms as thermal coupling "enclosure-heat source" is of particular importance in the field of building physics. Accurate description of thermal coupling "enclosure-heat source" allows to predict the induced air flow inside heated rooms. This leads also to good assessments of thermal comfort as well as indoor air quality. On the other hand, suitable representations of the thermal behavior of heated rooms facilitate to assess the heat transfer phenomena that take place across the building envelope. Consequently, the energy consumption will be accurately evaluated. In addition, such analyses allow to optimize the design of heating systems.

On the other hand, the results of this study show (at least for the configuration taken into consideration here) that there is no sensitivity of radiative heat flux to the walls of the room to angular discretization used in the radiation model. This finding is interesting because high levels of angular discretization for the radiation models in CFD simulations lead to important additional CPU (central processing unit) time. For example, the CPU time required for the simulations carried out in this study with five control angles for each octant in the computational domain is two times higher, compared to the CPU time for simulations with only two control angles.

This means that for relatively simple geometries, as usually meet in buildings, minimum angular discretization can be employed for the radiation model in CFD simulations, achieving significant savings in CPU time. However, this conclusion must be checked by further work for other configurations.

\section{References}

[1] K.S. Kwon, I.B. Lee, H.T. Han, C.Y. Shin, H.S. Hwang, S.W. Hong, J.P. Bitog, I.H. Seo, and C.P. Han, "Analysing ventilation efficiency in a test chamber using age-of-air concept and CFD technology", Biosystems Engineering, vol. 110(4), pp. 421-433, 2011.
[2] M. Aghakhani, and G. Eslami, "Thermal comfort Assessment of Underfloor vs. Overhead Air Distribution System", Journal of Applied Sciences, vol. 12, pp. 473-479, 2012.

[3] T. Kim, S. Kato, and S. Murakami, "Indoor cooling/heating load analysis based on coupled simulation of convection, radiation and HVAC control", Building and Environment, vol. 36, pp. 901-908, 2001.

[4] T. Catalina, J. Virgone, and F. Kuznik, "Evaluation of thermal comfort using combined CFD and experimentation study in a test room equipped with a cooling ceiling", Building and Environment, vol. 44, pp. 17401750, 2009.

[5] M.D. Ahanj, M. Rahimi, and A.A. Alsairafi, "CFD modeling of a radiant tube heater", International Communications in Heat and Mass Transfer, vol. 39, pp. 432-438, 2012.

[6] R. Gao, A. Li, O. Zhang, and H. Zhang, "Comparison of indoor air temperatures of different under-floor heating pipe layouts", Energy Conversion and Management, vol. 52, pp. 1295-1304, 2011.

[7] A. Ploskic, and S. Holmberg, "Heat emission from thermal skirting boards", Building and Environment, vol. 45, pp. 1123-1133, 2010.

[8] F. Moukalled, S. Verma, and M. Darwish, "The use of CFD for predicting and optimizing the performance of air conditioning equipment", International Journal of Heat and Mass Transfer, vol. 54, pp. 549-563, 2011.

[9] C. Inard, "Contribution to the study of the thermal coupling of a heat emitter with a room", Ph.D. Thesis, INSA Lyon, France, 1988.

[10] C. Teodosiu, D. David, R. Teodosiu, "Numerical prediction of thermoaeraulic behavior for a cavity with internal linear heat source", Scientia Iranica - Transaction B: Mechanical Engineering, in press, 2015.

[11] F.R. Menter, R.B. Langtry, S.R. Likki, Y.B. Suzen, P.G. Huang, and S. Volker, "A Correlation-Based Transition Model Using Local Variables Part I: Model Formulation", Journal of Turbomachinery, vol. 128, pp. 413-422, 2006.

[12] F.R. Menter, "Two-equation eddy-viscosity turbulence models for engineering applications", AIAA Journal, vol. 32, pp. 1598-1605, 1994.

[13] R. Siegel, and J.R. Howell, Thermal radiation heat transfer. Taylor \& Francis, Washington DC, USA, 1992.

[14] Ansys Inc., ANSYS Fluent User's Guide - Release 15.0, Ansys Inc., Canonsburg (PA), USA, 2013.

[15] C. Teodosiu, F. Kuznik, and R. Teodosiu, "CFD modeling of buoyancy driven cavities with internal heat source - Application to heated rooms", Energy and Buildings, vol. 68, pp. 403-411, 2014.

About Author (s):

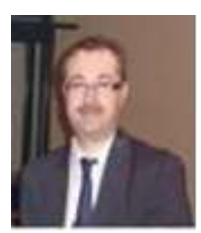

\section{Catalin Teodosiu}

Organizations and experience: Vice-president of Romanian Association of Building Services Engineers (AIIR) - Bucharest Subsidiary (from 2010); Associate Professor (from 2007), lecturer (2004-2007), assistant lecturer (1996-1998) in Thermo-Hydraulic and Protection of the Atmosphere Systems Department, Faculty of Building Services and Equipment, Technical University of Civil Engineering, Bucharest; assistant lecturer (2002-2004) in National Institute of Applied Science (INSA) Lyon; assistant lecturer (2001-2002) in University Claude Bernard - Lyon I; Ph. D. (1998-2001) in INSA Lyon; author or co-author of 4 books and university courses; over 55 articles in international and national journals and papers in peer-reviewed international conferences proceedings; over 30 international or national researchdevelopment-innovation projects ( 6 as project manager/responsible). Relevant research work:

C. Teodosiu, V. Ilie, R.G. Dumitru, R. Teodosiu. Assessment of ventilation efficiency for emergency situations in subway systems by CFD modeling. Building Simulation, in press; doi: 10.1007/s12273-015-0269-9

C. Teodosiu, F. Kuznik and R. Teodosiu. CFD modeling of buoyancy driven cavities with internal heat source - Application to heated rooms. Energy and Buildings, 2014; 68:403411

C. Teodosiu. Modeling and simulation of technical systems in the field of building equipment (216 pages), Matrix ROM, Bucharest, 2007 (ISBN 978-973-755-182-5)

Current research: CFD (Computational Fluid Dynamics) modeling, focusing on turbulence models and integrated heat-airflow-moisture models; building simulation; high efficiency buildings 


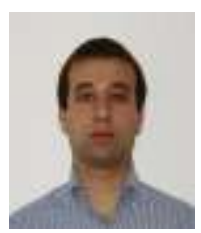

\section{Viorel Ilie}

Organizations and experience: Ph.D. Student (from 2013) - Thermo-Hydraulic and Protection of the Atmosphere Systems Department, Faculty of Building Services and Equipment, Technical University of Civil Engineering, Bucharest; M. Sc. degree in Energy Efficiency of Buildings (2011-2013), Technical University of Civil Engineering (Building Services Faculty), Bucharest. Relevant research work:

C. Teodosiu, V. Ilie and R. Teodosiu. Appropriate CFD turbulence model for improving indoor air quality of ventilated spaces. Mathematical Modelling in Civil Engineering, 2014; 10(4):28-42

R. Teodosiu, V. Ilie and C. Teodosiu. Computational Fluid Dynamics prediction of indoor air quality. International Journal of Material Science \& Engineering - IJMSE, $2015 ; 2(1): 58-62$

C. Teodosiu, V. Ilie and R. Teodosiu. Condensation Model for Application of Computational Fluid Dynamics in Buildings. International Journal of Materials, Mechanics and Manufacturing, 2015; 3(2):129-133

Current research: CFD (Computational Fluid Dynamics) modeling; ventilation systems efficiency.

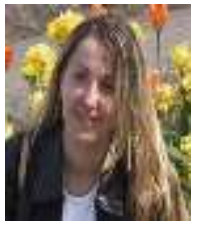

\section{Raluca Teodosiu}

Organizations and experience: Scientific Secretary of Energy Auditors Order Romania, OAER (from 2011); Lecturer (from 2004) in Thermo-Hydraulic and Protection of the Atmosphere Systems Department, Faculty of Building Services and Equipment, Technical University of Civil Engineering,
Bucharest; assistant lecturer (2003-2004) in University Claude Bernard Lyon I; Ph. D. (2000-2003) in INSA Lyon; over 40 articles in international and national journals and papers in peer-reviewed international conferences proceedings; over 10 international or national research-developmentinnovation projects (1 as project manager/responsible). Relevant research work:

C. Teodosiu, L. Niculiță and R. Teodosiu. Solutions for Energy Conservation and Pollution Reduction: Earth-Air Heat Exchangers. International Journal of Environmental Science and Development, 2015; 6(7):484-490

C. Teodosiu, V. Ilie and R. Teodosiu. Modeling of Water Vapor Sources in Enclosures. International Journal of Structural and Civil Engineering Research - IJSCER, 2015; 4(2):212-217

R. Teodosiu. Integrated moisture (including condensation) - Energy-airflow model within enclosures. Experimental validation. Building and Environment, 2013; 61:197-209 Current research: CFD (Computational Fluid Dynamics) modeling, experimental investigations concerning indoor air quality; thermal-aeraulic behavior of buildings; energy consumption of buildings. 